Autora para contato: acris.fidelis@gmail.com

\title{
A Relação entre Felicidade e Trabalho: Um Estudo Exploratório com Profissionais Ativos e Aposentados
}

La relación entre felicidad y trabajo: um estúdio exploratório com profesionales activos y jubilados

The Relationship Between Happiness and Work: An Exploratory Study with Active and Retired Professionals

Andréa Cristina Fermiano Fidelis

Universidade de Aveiro-Aveiro - Portugal

Antonio Jorge Fernandes

Universidade de Aveiro - Aveiro - Portugal

Priscila Bresolin Tisott

Universidade de Caxias do Sul - Rio Grande do Sul-Brasil

\section{RESUMO}

A partir da Psicologia Organizacional Positiva, os estudos das organizações vêm explorando assuntos relacionados àsubjetividade dos funcionários e suas relações com o resultado das empresas. Nesta perspectivateórica, esta pesquisa elegeu os temas Trabalho e Felicidadecom o objetivo de identificar a relação entre estes dois conceitos na perspectivados trabalhadores. Através da abordagem qualitativa - exploratória, com entrevistas abertas e semiestruturadas foram ouvidas doze pessoas, homens e mulheres, com idades entre 30 e 65 anos, sendoseis trabalhadores aposentados e seis trabalhadores ativos, com no mínimo 10 anos de exercício profissional na iniciativa privada. A análise das entrevistas foi realizada pelo método de Análise de Conteúdo. As conclusões versam que os respondentescompreendem Trabalho e Felicidade por uma perspectiva de realização pessoal e missão de vida. Aqueles que avaliaram suas vidas como felizes relacionam sua vida laboral (Trabalho) como fonte de realização pessoal e sentido de existência. Os resultados expressaram uma relação de conectividade entre os conceitos Felicidade e Trabalho, indicando interdependência entre eles.

Palavras-chave: Trabalho. Felicidade. Bem-Estar.

\section{RESUMEN}

A partir de la Psicología Organizacional Positiva, los estudios de las organizaciones vienen explorando asuntos relacionados ala subjetividad de los funcionarios y sus relaciones com el resultado de las empresas. En esta perspectiva teórica, esta investigación eligió los temas Trabajo y 
Felicidad con el objetivo de identificar la relación entre estos dos conceptos em la perspectiva de los trabajadores. Através de la bordajecualitativo-exploratorio, con entrevistas abiertas y semiestructuradas se escucharondoce personas, hombres y mujeres, con edades entre 30 y 65 años, siendo seis trabajadores jubilados y seis trabajadores activos, con al menos 10 años de ejercicio profesional en la iniciativa privada. El análisis de las entrevistas fue realizado por el método de Análisis de Contenido. Las conclusiones de los encuestados comprenden Trabajo y Felicidad por una perspectiva de realización personal y misión de vida. Aquellos que evaluaron sus vidas como felices relacionan su vida laboral (Trabajo) como fuente de realización personal y sentido de existencia. Los resultados expresaron una relación de conectividad entre los conceptos Felicidad y Trabajo, indicando interdependencia entre ellos.

Palabras-clave: Trabajo. Felicidad. Bienestar

\begin{abstract}
From the Positive Organizational Psychology, the studies of the organizations have been exploring subjects related to the subjectivity of the employees and their relation with the results of the companies. In this theoretical perspective, this research chose the themes Work and Happiness with the objective of identifying the relationship between these two concepts in the perspective of the workers. Through the qualitative - exploratory approach, with open and semi - structured questionnaire, twelve people, men and women, aged between 30 and 65 years old were interview. The sample consisted of six retired workers and six active workers, with at least 10 years of professional practice in the private sector. The analysis of the interviews was performed using the Content Analysis method. The conclusions are that respondents understand Work and Happiness from a perspective of personal fulfillment and mission of life. Those who have assessed their lives as happy relate their work life as a source of personal fulfillment and sense of existence. The results expressed a connectivity relation between the concepts of Happiness and Work, indicating interdependence between them.
\end{abstract}

Keywords: Work. Happiness. Well-being.

\section{Introdução}

A palavra "trabalho" deriva do latim 'tripalium', que designa um instrumento de tortura constituído de três estacas de madeira bastante afiadas, comum em tempos remotos na Europa. Originalmente 'trabalhar' significava 'ser torturado' e era realizado por pessoas desprovidas de qualquer posse (escravos). $\mathrm{Na}$ língua francesa o termo trabalho deriva da palavra 'travailler' significando sentir sofrimento ou dor, que também está relacionada à realização de uma atividade difícil e exaustiva (dicionário etimológico, 2015). Apesar deste nascimento traumático, o trabalho ocupa grande parte da vida adulta dos indivíduos na sociedade.
Os autores Miguiluchi e Gonçalves (2013) lembram que o trabalho está presente em qualquer organização humana, desde a préhistória até os dias de hoje. Na pré-história o ser humano trabalhava para se proteger dos perigos e sobreviver. Nos tempos atuais, as pessoas trabalham para produção de bens e serviços em troca de remuneração e sustento.

Já Borges, Alves-Filho e Tamayo (2008) discutem a questão do trabalho como um conceito subjetivo e complexo, que pode ser observado por várias perspectivas, sejam elas de natureza sociais, históricas, psicológicas ou filosóficas. Os autores afirmam que cada indivíduo constrói seu significado pessoal sobre o trabalho, tornando- 
o uma referência individual que confunde sua própria história pessoal e de vida com sua história laboral.

As pessoas ao falarem de si, dizem quem são, nomeiam suas funções e suas ocupações para descrever-se. Os autores Borges et al. (2008, p.217) confirmam esta relação entre trabalho e trabalhador quando escrevem:

Tal construção pelo indivíduo ocorre através do processo de socialização, na qual o indivíduo ativa e criativamente, apropria-se e recombina os elementos da realidade social e material, bem como das concepções (ideológicas) do trabalho, oriundas das formas de seu tempo histórico.

Ao nos referirmos ao nascimento do termo trabalho, que indicava tortura e sofrimento, a relação entre esta atividade parece ser irreconciliável com a ideia de felicidade, prazer ou mesmo realização pessoal. Porém, muitos estudos acadêmicos vêm se dedicando a explorar esta relação entre Felicidade e Trabalho na vida dos seres humanos (Bendassolli, 2007; Fisher, 2010; Rego \& Pina E Cunha, 2009; Seligman, 2012).

O autor Bendassolli (2007) observa esta relação paradoxal. $\mathrm{O}$ autor discute que na cultura nacional brasileira prevalece uma relação de amor e ódio com o trabalho laboral. Para ele, grande parte dos brasileiros almeja alcançar êxito financeiro, reconhecimento social e fama, refletido na busca do ideal moderno do sucesso. Este sucesso é propagado pela mídia e povoa o imaginário das pessoas. Segundo a visão de Bendassolli, a sociedade nacional capitalista interpreta que ser uma pessoa bem-sucedida é sinônimo de ter uma vida agitada, com status e dinheiro.

Como contraponto o indivíduo vive acossado pelo fantasma do medo do fracasso, buscando freneticamente alcançar este ideal do sucesso. Este drama humano do sucesso e do fracasso são experiências vividas, principalmente, no cenário do trabalho.
Já a palavra 'Felicidade' partiu do termo grego 'phyo' que quer dizer "produzir" (dicionário etimológico, 2015). O estudo da felicidade, por longos anos, pertenceu ao campo da filosofia, como conceito abstrato e hedônico. A partir do surgimento da abordagem da Psicologia Positiva passou a ser objeto de estudos privilegiado da área da Psicologia e do campo do Comportamento Organizacional (Ryan \&Deci, 2001; Snyder \&Lopez, 2009).

Neste artigo o termo Trabalho será compreendido como uma atividade laboral, remunerada, exercida pelos indivíduos adultos na sociedade. Já, o termo Felicidade será tratado como sinônimo de Bem-Estar subjetivo, alinhado as concepções teóricas da abordagem da Psicologia Positiva. Ambos os conceitos, Trabalho e Felicidade, terão suas dimensões subjetivas e pessoais respeitadas.

Com o propósito de identificar como os trabalhadores ativos e aposentados definem os construtos Trabalho e Felicidade, e qual a relação que eles indicam entre esses dois conceitos, foi realizada uma pesquisa exploratória- descritiva, de natureza qualitativa com doze pessoas. Os respondentes foram convidados a refletir sobre o tema, respondendo um questionário aberto, semiestruturado. Suas respostas foram ponderadas através do método de análise de conteúdo, conforme disposto por Bardin (2004). Neste texto será apresentada uma breve descrição teórica sobre a relação entre Trabalho e Felicidade, seguido do método aplicado e análise dos resultados. Nas considerações finais serão dispostas algumas reflexões realizadas pelos autores sobre este tema e sugestões de pesquisas futuras.

\section{Felicidade}

A Felicidade é descrita como um conceito subjetivo, sendo definido por perspectivas pessoais e culturais diferentes de sociedade para sociedade. Existem correntes teóricas que acreditam que a Felicidade é a busca por prazer e satisfação. Outras correntes entendem este conceito como ausência de dor 
e sofrimento. Há, ainda, estudiosos que escrevem sobre a Felicidade como uma busca do indivíduo pelo equilíbrio na vida, por encontrar um sentido para sua existência, vivendo com paz e prosperidade (Ryan \&Deci, 2001; Snyder \&Lopez, 2009).

Por falta de consenso o termo Felicidade muitas vezes é usado como sinônimo para o termo Bem-Estar subjetivo. Kim-Prieto, Diener, Tamir, Scollon e Diener (2013) utilizaram estes termos como sinônimos em seu estudo. Para estes autores o Bem-Estar subjetivo pode ser medido e pesquisado através da compreensão das reações emocionais e julgamentos dos eventos da vida dos indivíduos. Os pesquisadores sustentam que a sensação de Bem-Estar ou Felicidade é uma análise subjetiva que a pessoa realiza ao rememorar fatos vividos, interpretando-os como positivos ou negativos, dando pesos para as experiências, traduzindoas como felicidade ou infelicidade.

Já, os autores que trabalham dentro da perspectiva da Psicologia Positiva, como Seligman (2012), por exemplo, postulam que há diferenças entre estes dois termos (BemEstar e Felicidade). O Bem-Estar é conceituado como um construto mais amplo que Felicidade. Para o autor o Bem-Estar é a possibilidade que os sujeitos têm de avaliar suas vidas através das realizações de projetos pessoais e da qualidade das relações que construiu ao longo de sua história, mesmo que por vezes não tenha sentido emoções agradáveis e positivas.

Seligman (2012) define Felicidade através de três aspectos: emoções positivas, engajamento e sentido na vida. Emoções positivas são os sentimentos sentidos de forma agradável como as sensações de conforto, de prazer, entusiasmo. O engajamento é entregarse completamente a uma atividade, envolverse. Já o sentido na vida é envolver-se, pertencer e servir a algo maior que a si próprio, e viver conforme um propósito. $\mathrm{O}$ autor indica que a Felicidade é uma medida que está intimamente ligada com a sensação de satisfação com a vida vivida.
Já a definição de Bem-Estar (Wellbeing) incorpora estes três aspectos apresentados (emoções positivas, engajamento e sentido) e mais as dimensões 'Realização e Relacionamentos Positivos'. Seligman afirma que a vida agradável e com significado não esgota o que os indivíduos buscam para si. As Realizações Pessoais e Relacionamentos são perseguidos e fazem parte do universo humano, independente de produzirem sensações hedônicas.

Estas dimensões são definidas da seguinte forma:

a) Relacionamentos Positivos: é a intenção de estar com as pessoas ou relacionar-se com outros indivíduos. O ser humano é um ser gregário por natureza, busca pertencer a um grupo e estar ligada a núcleos de pertença como amigos, família, etc. Esta também é uma tendência humana que move os indivíduos independentemente dos sentimentos positivos, engajamento ou sentido na vida.

b) Realização: é compreendida pela busca do sucesso, da vitória, da conquista e do domínio. $\mathrm{O}$ autor relembra que as pessoas que perseguem a Realização podem estar impregnadas de emoções, da busca pelo prazer ou mesmo com a intenção de dar sentido a sua vida, contudo, a realização (ou conquista) é buscada por ela própria, independentemente de produzir qualquer emoção positiva, sentido de vida ou relacionamentos positivos.

\section{Relação entre Trabalho e Felicidade}

Rego e Cunha (2012) apontam que muitas pesquisas procuram entender o que faz as pessoas serem mais felizes que outras. As perspectivas estudadas têm orientações teóricas diversas como aspectos biológicos, através da neurociência, aspectos sociais, através da cultura local ou aspectos individuais, que exploram traços ou estados de personalidade.

$\mathrm{Na}$ área das organizações, a Felicidade também tem sido objeto de pesquisa. Os 
autores Rego e Cunha (2012) defendem que, apesar de um emprego ou atividade não possa ser considerado o responsável pela felicidade dos indivíduos, uma pessoa não pode ser genuinamente feliz se ela estiver infeliz no trabalho.

No mesmo contexto, Seligman (2012) descreve que o Bem-Estar subjetivo ou a Felicidade podem ser conquistados e materializados através de uma vida produtiva, preferencialmente pelo trabalho. Para o autor, é através do trabalho que o ser humano pode conviver com os demais, engajar-se, buscar sentido e realização pessoal.

Bendassolli (2007, p. 60) corrobora este pensamento quando afirma que "o mais importante, para a felicidade no trabalho, é a atividade em si, e não o modo como ela se institucionaliza." Neste contexto, o trabalho e a felicidade estão intimamente ligados, tendo uma relação interdependente entre eles.

Os autores Moynihan, DeLeire e Enami (2015) em uma pesquisa longitudinal sobre o comportamento pró social dos sujeitos, afirmam que a Felicidade está associada a crença pessoal de cada indivíduo sobre a capacidade de produzir impacto positivo na vida da comunidade através de seu trabalho e de sua atividade laboral.

Já a autora Fisher (2010) conduz sua pesquisa sobre felicidade e trabalho na perspectiva organizacional. Para ela, empresas voltadas ao bem-estar de seus funcionários, propiciam um clima organizacional que estimula o sentimento de Bem-Estar levando seus colaboradores a desempenharem suas atividades com maior comprometimento, qualidade e criatividade.Talvez, por estas questões apresentadas por Fisher, os temas Felicidade e Trabalho têm sido alvo de interesse dos pesquisadores na área da Administração.

O autor Coutinho (2014), a luz do comportamento das pessoas nas empresas, acredita que o Bem-Estar subjetivo é fator crítico para o sucesso de qualquer instituição.
Em sua pesquisa, o autor apresenta investigações empíricas que confirmam que as organizações que consideram a Felicidade e Bem-Estar de seus colaborados exibem uma melhora no desempenho, resultados econômicos mais estáveis, menores índices de rotatividade e maior engajamento entre seus funcionários.

$\mathrm{Na}$ intenção de compreender quais são as causas e os resultados da felicidade para as pessoas e sua relação com o trabalho, Fisher (2010) percebeu que este sentimento de BemEstar tinha consequências positivas tanto para o indivíduo quanto para a organização em que ele trabalha, melhorando o engajamento, a qualidade e o desempenho dos trabalhadores.

Segunda a autora Fischer (2010) a felicidade no trabalho é mais que a satisfação do empregado com sua função (job satisfaction). Para ela a Felicidade dos colaboradores manifesta-se em três aspectos, a saber: satisfação no emprego, o engajamento e o comprometimento organizacional.

A partir desta descoberta Fisher (2010) identificou que algumas empresas promoviam ambientes felizes, conquistando resultados e desempenho elevados. A autora denominou estas organizações como "Empresas Felizes". Os traços comuns destas "Empresas Felizes" são: 1- apresentam culturas apoiantes e baseadas no respeito; 2 - proporcionam lideranças competentes a todos os níveis; 3 proporciona aos seus membros um tratamento justo, segurança de trabalho e reconhecimento; 4-organizam o trabalho de forma que este seja interessante e motivador; 5 - facilitam a aquisição e o desenvolvimento de competências; 6- selecionam as pessoas de acordo com a sua adequação ao trabalho e à organização; 7- trabalham essa adequação através de práticas de indução e socialização;8- reduzem os pequenos incômodos diários e procuram aumentar os fatores de satisfação; 9- persuadem os seus membros de que é possível trabalhar em ambientes não ideais, ou seja, lidam com a ideia de que as instituições não são perfeitas; 
10- adotam práticas de gestão de alto desempenho.

Stansfeld, Shipley, Head, Fuhrer e Kivimaki (2013) defendem que políticas para desenvolver um ambiente organizacional positivo, com incremento das relações interpessoais melhoram o sentimento de BemEstar dos empregados. Cunha, Rego e Lopez (2013) e Taranowski (2011) apresentam como conclusão em suas pesquisas empíricas que a relação Trabalho e Felicidade (ou Bem-Estar subjetivo) são cruciais para o sucesso e desempenho organizacionais. Os autores, embasados na concepção de Fischer (2010) acreditam que as "Organizações Felizes" ou "Empresa Feliz" são aquelas que combinam gestão de alta qualidade e desempenho com uma orientação humanista em suas ações.

Isto se confirma quando Cunha, Rego e Lopes (2013, p. 233) explicam que "boas práticas de gestão sem orientação humanizada acabam por gerar espaços organizacionais cínicos, pouco cooperativos, e pouco resilientes para enfrentar oportunidades, desafios e crises - o que, mais cedo ou mais tarde, se repercute negativamente no desempenho e na competitividade."

Os mesmos autores defendem que as "Empresas Felizes" revelam seis dimensões no seu clima organizacional que colaboram para o Bem-Estar subjetivo de seus funcionários, propiciando assim maior satisfação no trabalho, maior engajamento, menor índice de afastamento por doença dos empregados (empresa saudável), menor rotatividade, maior estabilidade financeira das organizações. As seis dimensões que colaboram para um clima organizacional que propicia Bem-Estar dos empregados são:

a) Cuidado/Espírito de Camaradagem: os funcionários são vistos nas suas necessidades e sentem o respeito e a amizade de seus colegas; percebem que seus colegas atuam com atenção e amizade.

b) Verdade e Apoio compassivo: a comunicação é baseada na verdade, sendo fluida. Os trabalhadores apoiam-se mutuamente, sendo compreensivos com aquelas que enfrentam problemas ou dificuldades.

c) Perdão: os trabalhadores reconhecem os deslizes e os erros de seus colegas, mas tomam atitudes de entendimento e evitam culpar uns aos outros pelas falhas que ocasionalmente ocorrem.

d) Inspiração: Os colegas servem de inspiração uns aos outros no trabalho.

e) Significado: O trabalho realizado pelas pessoas tem relevância e significado para as suas vidas, dando sentido a elas.

f) Gratidão e confiança: Os trabalhadores tratam-se mutuamente com respeito e apreciação mútua.

Outro aspecto relevante apontado pelos autores Rego e Cunha (2012), Cunha, Rego e Lopes (2013) e Matthews, Wayne e Ford (2014) para a conquista e manutenção do sentimento de Felicidade dos trabalhadores é a conciliação entre trabalho e família. Quando existe conflito nesta área o empregado fica propenso ao estresse, ao desinteresse e a baixa produtividade.

Por outro lado, reforçam os autores Rego e Cunha (2009), que quando existe a possibilidade de conciliação trabalho-família, os funcionários sentem-se apoiados pela organização, mais fortemente engajados em seus papéis profissionais, valorizando a empresa e seu trabalho, fortalecendo sua autoestima e senso de competência. Estes sentimentos positivos produzem a sensação de Bem-Estar subjetivo e Felicidade.

Apesar de crescentes pesquisas que demonstram estar focadas em estudar o BemEstar e Felicidade dos trabalhadores, Cunha, Rego e Lopes (2013) lembram que os estudos humanistas e identificados com a positividade e as forças das pessoas e organizações convivem com um olhar tradicionalmente negativo que trata os sujeitos como meros recursos a serem administrados. 
Welch e Welch (2005), autor influente na administração atual, admite em seu livro "Paixão por Vencer" que a felicidade dos colaboradores são discursos interessantes das organizações para atraírem funcionários. Contudo, na prática, as empresas esperam que o equilíbrio entre vida pessoal e trabalho seja um problema exclusivo do empregado e que estas questões não são bem-vindas no contexto da empresa.

Os autores dirigindo-se ao leitor individual, aconselham:

a mais alta prioridade de seu chefe é competitividade. Evidentemente, ele quer que você seja feliz, mas apenas na medida em que contribuir para a vitória da empresa. Na verdade, se ele (o funcionário) estiver trabalhando bem, o seu trabalho, por sua vez, será tão vibrante que sua vida pessoal se transformará em algo menos premente (Welch \&Welch, 2005, p.288).

Com a intenção de valorizar as pessoas e sua contribuição no contexto organizacional, os estudos com o tema da Felicidade e BemEstar subjetivo no trabalho podem indicar um caminho alternativo para as empresas que desejem desenvolver práticas de gestão e criação de ambientes organizacionais mais humanos.

Este cenário humanista tem-se mostrado eficaz em promover aumento do desempenho dos trabalhadores, bem como um diferencial competitivo acompanhados com resultados econômicos - financeiro almejados. Como apontam os autores Cunha, Rego e Lopez (2013) as conquistas das empresas com foco no potencial humano e sua atenção à Felicidade e Bem-Estar de seus funcionários leva a concluir que "pode ser bom ser bom".

\section{Método}

Com o objetivo de conhecer qual a relação entre Trabalho e Felicidade, foi realizado um estudo exploratório- descritivo, de natureza qualitativa. É de cunho exploratório para que seja possível identificar ou refinar problemas de pesquisa que podem auxiliar na formulação e teste de estruturas conceituais. De natureza qualitativa, por permitir recolher informações novas, através da fala espontânea e da observação no contexto social (Chizzotti, 2003).

A amostra foi composta por 12indivíduos, com vínculo empregatício ou aposentados, que trabalham ou trabalharam, no mínimo, mais de 10 anos na iniciativa privada brasileira. Os respondentes foram convidados a refletir sobre as seguintes questões: 1- O que é Trabalho para você?; 2 O que é Felicidade para você?; 3- Qual a relação entre Trabalho e Felicidade?; 4- Em que o Trabalho poderia contribuir para você ficar mais feliz?

Este questionário possibilitou a obtenção de respostas, com entendimento conceitual do tema abordado, aferido por meio das entrevistas que foram gravadas $\mathrm{e}$ transcritas em forma de texto, conforme apontados por Lankshear e Knobel (2008). Optou-se por uma análise qualitativa de conteúdo por compreender que esta forma seria mais adequada para alcançar os objetivos propostos. Segundo Bardin (2004, p. 37) a análise de conteúdo é:

um conjunto de técnicos de análise das comunicações visando obter, por procedimentos sistemáticos e objetivos de descrição do conteúdo das mensagens, indicadores (quantitativos ou não) que permitam a inferência de conhecimentos relativos às condições de produção/recepção (variáveis inferidas) destas mensagens.

Conforme o modelo descrito por Bardin (2004) foram definidas categorias de análise a priori tais como conceito de Trabalho, conceito de Felicidade, a relação entre estes dois conceitos e contribuição do trabalho para (in)Felicidade. A análise de conteúdo como um conjunto de técnicas de 
análise baseadas na explicitação e sistematização do conteúdo das mensagens e a partir destas abordagens, possibilita efetuar deduções lógicas e justificadas relativas à origem das mensagens inseridas no contexto explorado.

As respostas dos entrevistados serão relacionadas no texto deste estudo pela letra $\mathrm{R}$ (significando respondente) seguido de um número identificador de 01 a 12, que está distinguindo cada pessoa que participou desta pesquisa. As falas serão reproduzidas por escrito nas discussões de resultado exatamente como foram recitadas. Os resumos das principais declarações dos respondentes encontram-se no Anexo A, ao final deste artigo. As características da amostra estão relacionadas conforme a tabela abaixo.

\begin{tabular}{|c|c|c|c|c|}
\hline \multicolumn{2}{|c|}{ Quadro 01 - Caracterização da amostra } \\
\hline Situação & Escolaridade & $\begin{array}{c}\mathrm{N}^{\circ} \\
\text { participantes }\end{array}$ & $\begin{array}{c}\text { Gênero } \\
\text { masculino }\end{array}$ & $\begin{array}{c}\text { Gênero } \\
\text { Feminino }\end{array}$ \\
\hline Aposentados & Superior completo & 5 & 1 & 5 \\
\hline Ativos & Superior completo & 4 & 3 & 2 \\
\hline Ativos & Sem superior completo & 3 & 0 & 1 \\
\hline TOTAL & & 12 & 4 & 8 \\
\hline
\end{tabular}

Figura 1: Detalhes da revisão de literatura

\section{Apresentação e Discussão dos Resultados}

O conceito Trabalho foi definido prioritariamente pelos respondentes como uma atividade conectada com a realização pessoal, prazer e missão de vida. Observou-se que, das doze pessoas entrevistadas, apenas três (R02; R07; R09) referiram Trabalho como obrigação e necessidade financeira, desvinculado da realização pessoal.

Para os entrevistados trabalhar é uma oportunidade de realizar algo com significado. Esta realização, não está só no dar sentido a suas vidas ou num trabalho com significado social, mas o de trabalhar fazendo o que escolheram fazer, refletidas em atividades prazerosas. Aliados a estes sentimentos, os respondentes também comentaram o sentimento de orgulho de ter provido financeiramente suas famílias e a si próprios através de suas atividades laborais.Estas afirmações corroboram as pesquisas de Seligman (2012) e Borges et al., (2008) citadas no corpo deste texto.
A Felicidade foi relacionada com quatro ideias principais: de realização pessoal (04 respostas), estar com pessoas (04 respostas), ser consequência do trabalho (03 respostas) e estar em paz consigo mesmo (03 respostas).

Entretanto, quando solicitado aos entrevistados para explicarem mais profundamente estas quatro ideias principais, o tema família é fala recorrente. As respostas citam que a família é o elemento fundamental para ser feliz. A referência a família remete aos estudos dos autores Rego e Cunha (2012), Cunha, Rego e Lopes (2013) e Matthews, Wayne e Ford (2014, confirmando que esta unidade social tem relevância no sentimento subjetivo de Bem-Estar.

É interessante notar que o conceito hedônico de Felicidade prazerosa e egocêntrica não foi citado. Na construção deste conceito de Felicidade, prevaleceram entre os entrevistados, as colocações sobre a necessidade de convivência com outras pessoas, através da família e dos amigos ou da 
realização pessoal através do sentido de vida. Os respondentes contavam suas experiências de trabalho e de vida atribuindo sentido as ações vivenciadas por eles.

As respostas referentes à relação entre Trabalho e a Felicidade corroboram as afirmações de Rego e Cunha (2009) e Fisher (2010), ou seja, de que existe uma relação direta e interdependente entre esses dois conceitos.

Os respondentes referendaram que o trabalho produz felicidade quando o mesmo é vivido como realização pessoal. Para que ela se realize é necessário que a pessoa faça o que gosta, faça aquilo que escolheu como atividade, o que lhe dá prazer no dia a dia. A referência em 'fazer o que se gosta', em escolher o que se faz no trabalho apareceu em todas as falas dos respondentes, independente da escolaridade, função ou do tempo de serviço.

Os indivíduos que afirmaram não gostar do seu trabalho identificaram sua infelicidade por estarem atrelados a algo que não os realiza, que não gostam de fazer. Estes últimos, que não gostam das atividades que estão exercendo, afirmam suas intenções de trocarem de empresa e de estarem direcionando seus esforços para encontrarem outra carreira ou outra função.

Este sentimento de insatisfação com o trabalho relatado por alguns respondentes confirmam as evidências apontadas por Fisher (2010) e Rego e Cunha (2009) em que funcionários infelizes não estão engajados em suas atividades, aumentando a possibilidade de sair da empresa (rotatividade).

No critério - contribuição do trabalho para infelicidade ou felicidade - àqueles que indicaram o desejo de ter maiores recursos, como materiais e equipamentos, para realizarem suas atividades com maior competência, são os que trabalharam em empresas com menor estrutura financeira. Estes também relacionavam suas atividades como prazerosas e cheias de significado.

As pessoas que referiram aumentar o retorno financeiro (dois respondentes) também referiram que não estão satisfeitos com suas atividades, vendo-as como transitória, tendo intenção de mudar de empresa ou de função. Novamente, as respostas a esta questão confirmam que o engajamento, o sentido e sentimentos positivos estão diretamente ligados à felicidade percebida no trabalho. Quando estes sentimentos não estão conectados a vida laboral, não há a preocupação de fazer o melhor possível ou em estar buscando qualidade e aperfeiçoamento no exercício de suas funções.

Quando a amostra foi analisada somente no segmento aposentados, dentre os seis respondentes nesta condição, quatro vêem o trabalho como missão de vida e realização pessoal. Estes relacionam a Felicidade a três situações: ao trabalho, a realização profissional integrada com a realização na vida pessoal e a paz interior.

Ouvindo estas pessoas identificamos que eles falam de suas vidas misturadas a suas atividades laborais, rememorando-as, relatando os sentimentos que afloram ao contarem de suas profissões, dotando de significado e sentido suas vidas através de seu trabalho, conforme explorado por Borges et al., (2008). Sendo assim, os sujeitos que se identificaram como felizes são aqueles que enxergaram sua vida laboral como objetivo de vida, sentindo-se realizado e recompensado por seus atos através da sensação de paz de espírito e de missão cumprida. 
Todos os respondentes, aposentados e ativos, que definiram seus trabalhos como missão de vida também descreveram seus trabalhos como prazerosos. Estes mesmos respondentes, ao definirem Felicidade comentaram que o sentimento de Bem-Estar está diretamente relacionado com sua atividade no trabalho ecom sua realização pessoal. Exemplo disto tem os discursos do R01 e R09 que se seguem:

R01 - "ser feliz é estar em paz consigo mesma... é fazer o bem as pessoas (...) como eu fui muito feliz na profissão que eu escolhi... eu fazia do meu trabalho momentos de felicidade..."

R09 - "É estar num trabalho que gosta, que se sente bem (...) o trabalho tem que produzir felicidade para que o trabalho não seja só uma maneira de ganhar dinheiro... é mais importante ganhar dinheiro se realizando, sendo feliz do que simplesmente trabalhar para ganhar dinheiro, sei lá, se tornar escravo do trabalho."

Os respondentes que referiram o trabalho como necessidade financeira não relacionaram o conceito de Felicidade com realização pessoal. Para eles o conceito de Felicidade está relacionado com a conquista de bens materiais ou estar bem em família. Esta perspectiva é percebida nas respostas dos respondentes 02,06 e 07.

O discurso do Respondente 02 evidencia esta questão, quando diz: “... trabalho, hoje em dia, é uma forma de me sustentar, é um fardo (...) felicidade é tantas coisas é viver bem, é viajar, é poder sair com meus filhos."

Através das respostas colhidas nesta pesquisa as conclusões apontam que existe uma relação direta entre Trabalho e Felicidade. Esta indicação se confirma pela análise dos discursos. Todos os respondentes fizeram esta relação, informando que o trabalho propicia aos sujeitos fazer o que gostam, gerando prazer, satisfação e possibilitando dar sentido a suas vidas.

Esta conclusão está consoante à colocação de Bendassolli (2007) quando o autor escreve que a felicidade está na atividade em si e não na institucionalização da mesma.

Todos os entrevistados expressaram que, quando se faz o que se gosta no trabalho, este passa a produzir Felicidade, como dito pelo Respondente 05 - "trabalho e felicidade andam um do lado do outro, um proporciona o outro, não tem como eles serem separados."

Os conceitos de Seligman (2012) e Fisher (2010) também são identificados nos discursos dos entrevistados quando eles argumentam que a Felicidade no trabalho produz sentido a suas vidas, sentem-se realizados, gerando uma sensação de bemestar.

Da mesma forma, quando esta realização pessoal não se concretiza gera frustração e sofrimento para o indivíduo. $\mathrm{O}$ respondente 06 contextualiza seu sofrimento no trabalho e na vida ao dizer: "eu não estou feliz neste momento, por isso, mas eu acho que deveria ser uma coisa que se complementa: trabalho e felicidade."

O Respondente 07 exemplifica esta mesma questão quando explica: "Eu acredito que a grande maioria das pessoas não faz o que gosta. Então o trabalho é um peso e uma obrigação, porque muitos nem sabem o que gostam de fazer (...) e no trabalho o que eu gostaria de fazer é (...), é isto que eu gosto...".

As respostas, através das palavras chaves e das categorias pesquisadas, estão 
organizadas em um quadro temático dispostos no Anexo A.

\section{Considerações finais}

Cunha e Rego (2013) e Seligman (2012) lembram que o Bem-Estar subjetivo é percebido pelo trabalhador através da rememoração dos eventos vividos, dando significado para suas ações. $\mathrm{Na}$ fala dos entrevistados, é possível afirmar que o trabalho é uma oportunidade para que os indivíduos convivam e interajam com as pessoas, vejam sentido em suas ações, se engajem e se motivem nas suas tarefas, percebendo os frutos de suas atividades como realizações positivas.

Como exemplo deste sentimento tem a afirmação do Respondente 10, descrito a seguir - "o trabalho tem que ter um significado pra mim, para ter a felicidade (...) pra olhar as pessoas felizes, pra olhar o que eu faço lá (...) isto me traz um significado muito grande (...) quando tem este significado de ajudar o outro (...)".

Esta resposta descrita acima representa quanto à relação entre trabalho e felicidade estão relacionados na vida das pessoas. Trabalhar no que se gosta e no que se escolheu para fazer como atividade laboral, traduziu-se como conquista do sentimento de Bem-Estar e Felicidade, nesta pesquisa. Desta forma, os entrevistados reforçaram que a missão de vida, ou na definição de Seligman de sentido da vida, está intimamente relacionada à felicidade experimentada no contexto do trabalho.

Outro aspecto também percebido neste estudo foi de que os sentimentos do prazer pelo prazer (felicidade hedônica) não predominaram no discurso dos respondentes. A Felicidade pode ser prazer, porém não se limita a este sentimento. A busca por realização, por engajamento e por sentido são lembradas por todos os respondentes neste estudo.

A realização deste projeto propiciou a seus autores refletirem sobre a importância do
Trabalho laboral para a realização pessoal e Felicidade dos indivíduos na sociedade. A função que as pessoas desempenham na sua vida profissional é uma oportunidade de encontrar e sentir a Felicidade e o Bem-Estar. Por esta razão passamos a concordar com a afirmação de Felicidade, descrita por Seligman (2012), de que sentido, engajamento e sentimentos positivos encontram melhor expressão no contex to do trabalho.

Lembrando os conceitos de Rego e Cunha (2012) e Fischer (2010) sobre BemEstar subjetivo, também é possível afirmar que a experiência laboral oferece o cenário perfeito para os indivíduos experimentarem concretamente os relacionamentos entre os sujeitos, a camaradagem entre colegas, o perdão, a inspiração, a realização pessoal e outros aspectos da vida humana. Dado sua importância e no resultado que produz nas empresas, o Trabalho e a Felicidade devem ser estudados com maior atenção pelo ambiente organizacional.

Apesar de esta pesquisa ter respondido aos objetivos iniciais propostos, algumas questões intrigaram os pesquisadores. Ouvindo e analisando os discursos dos respondentes, foi percebido que as perguntas realizadas na entrevista semiestruturada estavam considerando apenas uma perspectiva pessoal e individual dos sujeitos em relação ao tema proposto. Seria oportuno examinar a influência do contexto organizacional nesta dinâmica entre Trabalho e Felicidade.

Neste pensamento, algumas dúvidas foram levantadas durante a realização do estudo, tais como: a felicidade do funcionário se sustenta em ambientes negativos, mesmo quando ele identifica sua atividade laboral como missão de vida e realização pessoal? Existe interferência na escolha da atividade prazerosa e ambiente de trabalho? Para pesquisas futuras sugere-se explorar estas questões bem como aprofundar a relação entre Trabalho e Felicidade, ou Trabalho e BemEstar subjetivo em diferentes empresas, com a 
intenção de verificar outras variáveis que possam interferir neste contexto.

\section{Referências}

Bardin, L. (2004). Análise de conteúdo. $3^{\mathrm{a}}$. Lisboa: Edições, 70.

Bendassolli, P. F. (2007). Felicidade e trabalho. GV-executivo, 6(4), p. 57-61.

Borges, L. O, Alves-Filho, A, Tamayo, A. (2008) Motivação e Significado do Trabalho. In: Siqueira, M. M. M. (2009). Medidas do comportamento organizacional: ferramentas de diagnóstico e de gestão. Artmed Editora.

Chizzotti, A. (2003). A pesquisa qualitativa em ciências humanas e sociais: evolução e desafios. Revista portuguesa de educação, 16(2).

Coutinho, M. R. C. P. (2014). A felicidade no trabalho: implicações no valor da empresa e no indivíduo (Doctoral dissertation, Tese de Doutorado. Instituto Superior de Gestão).

Cunha, M. P., Rego, A., \&Lopes, M. P. (2013). Comportamento organizacional positivo. Análise Psicológica, 31(4), p. 313-328.

Dicionário etimológico online (2015).

Recuperado de http://www.dicionarioetimologico.com.br.

Fisher, C. D. (2010). Happiness at work. International journal of management reviews, 12(4), p. 384-412.

Kim-Prieto, C., Diener, E., Tamir, M., Scollon, C., \&Diener, M. (2013). Integrating the diverse definitions of happiness: a time-sequential framework of subjective well-being. In:The Exploration of Happiness, p. 47-75. Springer Netherlands.

Lankshear, C., \&Knobel, M. (2008). Pesquisa pedagógica: do projeto à implementação.

Artmed.

Matthews, R. A., Wayne, J. H., \& Ford, M. T. (2014). A work-family conflict/subjective well-being process model: A test of competing theories of longitudinal effects. Journal of Applied Psychology, 99(6), p. 1173-1187.
Miquiluchi, J., \&Gonçalves, M. D. G. C. (2013). Estudo exploratório acerca da subjetividade na mensuração do sentimento de felicidade no trabalho: a visão de funcionários de uma agência bancária do interior do estado de São Paulo. UNIVERSITAS, (8).

Moynihan, D. P., DeLeire, T., \&Enami, K. (2015). A life worth living: Evidence on the relationship between prosocial values and happiness. The American Review of Public Administration, 45(3), p. 311-326.

Rego, A., \& e Cunha, M. P. (2012). They need to be different, they feel happier in authentizotic climates. Journal of Happiness Studies, 13(4), p. 701-727.

Rego, A., \& Pina e Cunha, M. (2009). Do the opportunities for learning and personal development lead to happiness? It depends on work-family conciliation. Journal of Occupational Health Psychology, 14(3), p. 334.

Ryan, R. M., \& Deci, E. L. (2001). On happiness and human potentials: A review of research on hedonic and eudaimonic well-being. Annual review of psychology, 52(1), p. 141-166.

Seligman, M. E. (2012). Florescer: Uma nova e visionária interpretação da felicidade e do bem-estar. Editora Objetiva.

Snyder, C. R., \&Lopez, S. J. (2009). Psicologia positiva. Porto Alegre: Artmed.

Stansfeld, S. A., Shipley, M. J., Head, J., Fuhrer, R., \&Kivimaki, M. (2013). Work characteristics and personal social support as determinants of subjective well-being. PLoS One, 8(11), e81115.

Taranowski, C. J. (2011). A Review of : "Pryce-Jones, J.(2010). Happiness at Work, Maximizing Your Psychological Capital for Success." West Sussex, UK: Wiley Blackwell, $241 \mathrm{p}$.

Welch, J., \& Welch, S. (2005). Paixão por vencer: winning.

Dados sobre os autores:

- Andréa Cristina Fermiano Fidelis é psicóloga graduada pela Universidade do Vale 
do Rio dos Sinos (Unisinos) e mestre em Administração pela Universidade de Caxias do Sul (UCS). Doutoranda em Marqueting e Estratégia pela Universidade de Aveiro (UA). Atuou como Gestora em Recursos Humanos em empresas do segmento de saúde e empresas de tecnologia. Trabalhou como docente em cursos de especialização e escolas técnicas, nas áreas de Psicologia aplicada à saúde e a gestão de Recursos Humanos.

- Antonio Jorge Fernandes é doutor em Economia Internacional e Desenvolvimento pela Universidade de Barcelona (1996 reconhecido pela UFMG em 2008), Mestre em Economia Rural pela Universidade Federal de Viçosa (1985) e Bacharel em Ciências Econômicas pela Universidade Estadual de Londrina (1980). Pesquisador e conferencista em congressos nacionais e internacionais em Economia do Turismo, Economia da Energia, Impactos Econômicos do Turismo, Gestão de Atrações Turísticas, Turismo e Sustentabilidade, Competitividade das Empresas e Energia, Avaliação e Custos de Projetos de Energia Eólica. Foi Professor Adjunto do Programa de Pós-Graduação em
Administração - PPGA e Programa de PósGraduação em Turismo- PPGTUR da Universidade de Caxias do Sul (UCS), nas linhas de pesquisa de Gestão da Inovação e Competitividade e Turismo, Organizações e Sustentabilidade no ano de 2014. Professor do Programa de Pós-Graduação em Administração da Universidade Potiguar em Natal. Professor do Departamento de Economia, Gestão e Engenharia Industrial da Universidade de Aveiro - Portugal. Experiência profissional na gestão acadêmica e administrativa no setor de ensino superior. Pesquisador da Unidade de Investigação Governança, Competitividade e Políticas Públicas (GOVCOPP) da Universidade de Aveiro - Portugal.

- Priscila Bresolin Tisott é bacharel em Comércio Internacional pela Universidade de Caxias do Sul (2012), mestre em Administração pela Universidade de Caxias do Sul (2015) e cursando Doutorado em Administração pela Universidade de Caxias do Sul, Rio Grande do Sul - Brasil. Bolsista PROSUP/ CAPES. Tem experiência na área de Comércio Internacional - Importação. 
Anexo A

\begin{tabular}{|c|c|c|c|c|c|c|c|c|c|c|c|c|}
\hline 밀 & 믈 & 밍 & प्ठ & ש్ఞ & z & 桇 & రृ & 꼬 & ¿्W & 미 & జ & \\
\hline 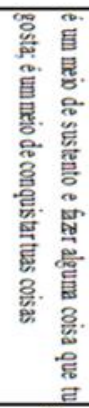 & 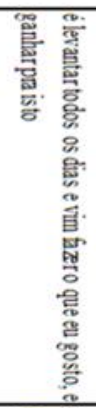 & 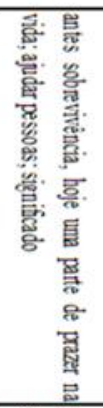 & 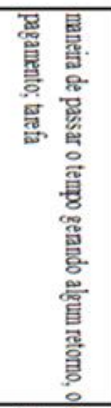 & 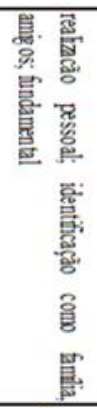 & 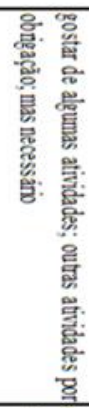 & 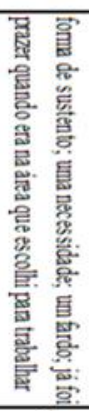 & 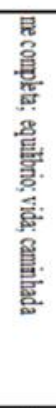 & $\begin{array}{l}\text { : } \\
\text { E. } \\
\text { 范 }\end{array}$ & 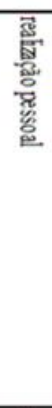 & 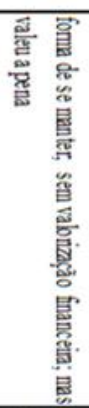 & 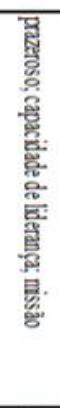 & 呇 \\
\hline 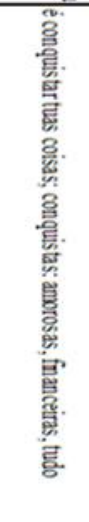 & 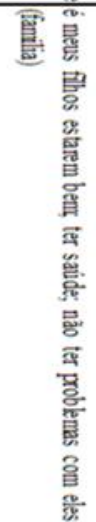 & 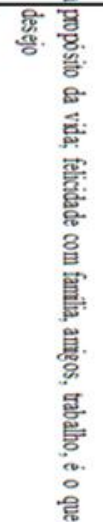 & 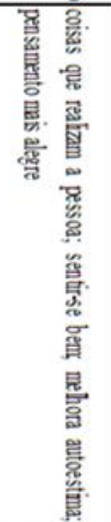 & 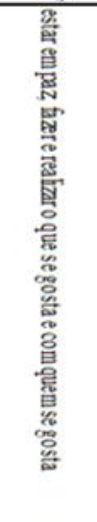 & 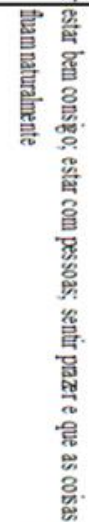 & 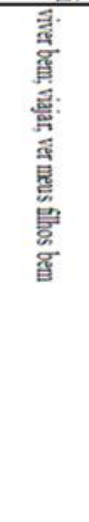 & 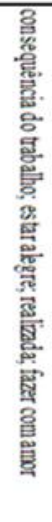 & 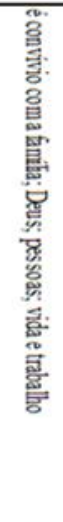 & 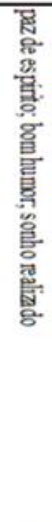 & 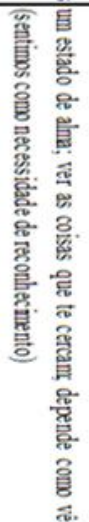 & 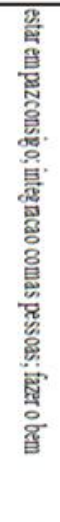 & \\
\hline 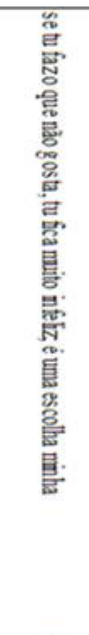 & 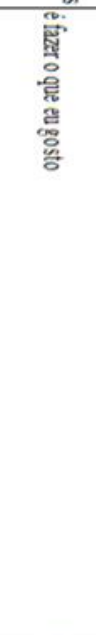 & 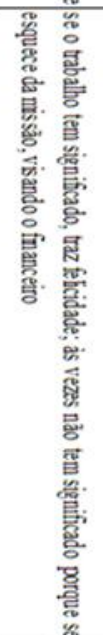 & 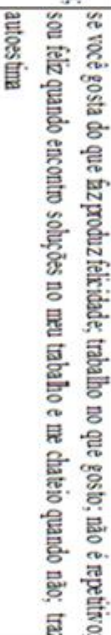 & 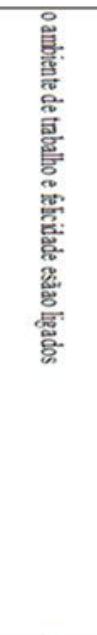 & 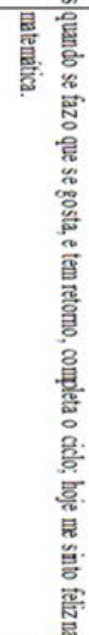 & 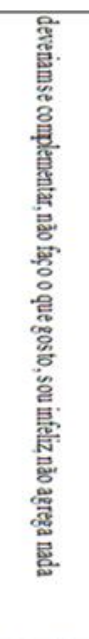 & 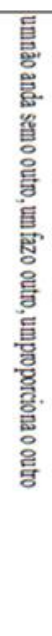 & 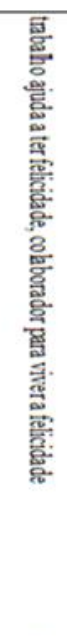 & 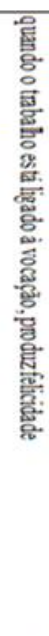 & 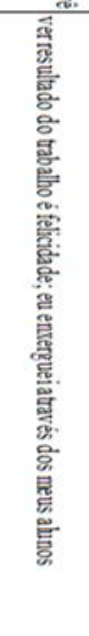 & 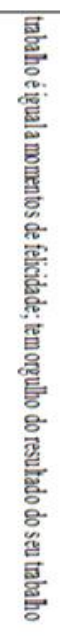 & 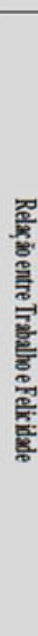 \\
\hline 苑 & 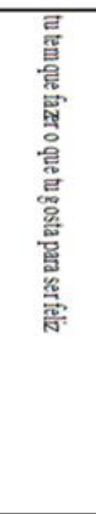 & 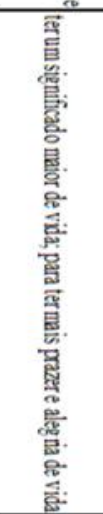 & 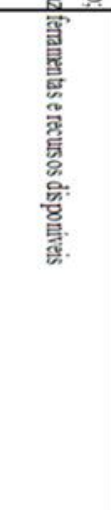 & 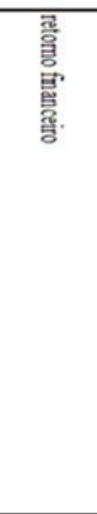 & 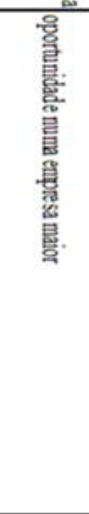 & 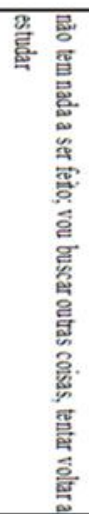 & 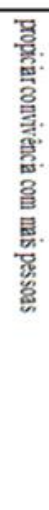 & 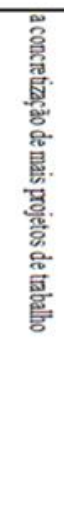 & 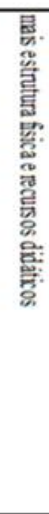 & 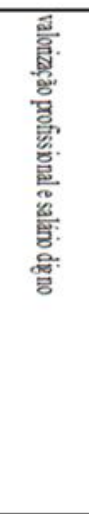 & 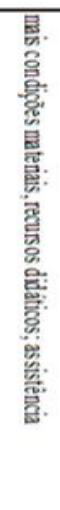 & \\
\hline
\end{tabular}

